micrograms a minute, with careful watch on the blood pressure.

The absolute eosinophil count may be a helpful guide to treatment but probably only after the first emergency is over. It is reasonable to aim at a count below 50 per cu. $\mathrm{mm}$. in the presence of stress.

5. The patient may be killed by an excess of salt, fluid or DCA ; the venous pressure does not give warning of this. Autopsy may reveal pleural and pericardial effusions when there was no rise of vẹnous pressure in life.

Chronic adrenal insufficiency is usually due to destruction or atrophy of the adrenal glands but it may complicate hypopituitarism and it may accompany adreno-genital virilism. In all these diseases cortisone has a rational place in maintenance treatment as well as in the treatment of crisis. Patients with Addison's disease need much less cortisone than patients with rheumatoid arthritis ; tuberculosis is probably not aggravated when cortisone is given in these physiological doses. Appetite improves, strength returns and mental powers increase. Hypoglycaemia is controlled. The risk of sudden crisis and death is diminished.

Acute adrenal insufficiency can be forestalled if one recognizes that any stress such as hard physical work, infection or operation leads to an increased demand for hormone. In a patient who cannot respond to this demand because he lacks adrenal glands large amounts of adrenal extract or cortisone should be given. Patients with adrenal atrophy secondary to hypopituitarism or with unilateral atrophy due to a contralateral tumour which is to be removed present a special case ; in them the adrenal glands may be stimulated with adreno-corticotropic hormone.

\title{
CORRESPONDENCE
}

\section{REQUEST FOR REPRINTS CONCERNING STRESS AND THE ADAPTIVE HORMONES}

DEAR SIR,

In perusing the current literature with which this journal is concerned, we note that an everincreasing number of its articles deals with problems pertaining to research on 'stress' and the so-called 'adaptive hormones' (ACTH, STH, corticoids, adrenergic substances, etc.).

We are writing you because, in our opinion, the success of research in this complex and rapidly developing field largely depends upon the prompt availability and evaluation of relevant publications, a task for which we should like to solicit the assistance of your readers.

In $195^{\circ}$ our Institute initiated the publication of a series of reference volumes entitled 'Annual . Reports on Stress' (Acta Medical Publishers, Montreal) in which the entire current world literature is surveyed every year (usually between 2,000 and 4,000 publications). Up to now we have had to compile the pertinent literature partly from medical periodicals, monographs, abstract journals and partly from reprints sent to us by the authors themselves. Of all these, reprints proved to be the best source of data which we felt deserved prompt attention in our annual reports. Hence, in the past, we have sent out several thousand individual reprint requests to authors of whom we knew that they are currently engaged in research on stress and allied topics. Even this procedure did not give us the wide coverage which would be desirable, because it is materially impossible to contact all these authors individually and it often takes too much time to get the requested reprints.

It is evident that in order to ensure prompt inclusion of publications in the annual reports, these surveys must develop into a co-operative effort between the authors of original papers and the reviewers. This co-operation has been greatly enhanced of late by the publication of announcements, in several medical journals, encouraging investigators interested in stress research to send us their reprints for this purpose as soon as they become available.

We should be grateful if by the publication of this note you would also bring this problem to the attention of your readers.

We are, Sir;

Very sincerely yours,

Hans Selye, M.D., Ph.D., D.Sc., F.R.S.(C.). Professor and Director of the Institute of Experimental Medicine and Surgery.

Alexander Horava, M.D.,

$$
\begin{gathered}
\text { Co-author of the 'Annual Reports on } \\
\text { Stress.' }
\end{gathered}
$$

